\title{
A terceira voz: por uma poética da tradução
}

Marcus Rogério Tavares Sampaio Salgado

UNB

\section{Resumo}

Para o teórico e tradutor português João Barrento, a poesia e a tradução de poesia são essencialmente fenômenos de $V O Z$, para os quais se pressupõe uma poética, na qual se detectam três situações-limite onde o gesto de verter se revela passível de analogias e correspondências com o próprio gesto de criar e onde o ato de enunciar se torna indissolúvel do ato de escuta. Assim, a criação poética e o ato de tradução se fazem a partir de uma concepção da literatura como comunidade textual, onde vozes comunicantes ecoam e interagem, num movimento dúplice de enunciação e escuta.

Palavras-chave: Poesia; Tradutologia; Poética.

\begin{abstract}
According to the Portuguese theoretician and translator JoãoBarreto, poetry and its translation are essentially voice phenomena that presuppose especific poetics (or a theory of poetry and of its translation) in which is possible to detect three limit situations where the gesture of translating reveals itself open to analogies and correspondences with the proper gesture of creating and where the act of enunciating is indissoluble to the act of hearing. Thus, poetical creation and translation are conceived out of the idea of literature as textual community, where communicating voices echo and interact in a double movement of enunciation and hearing.
\end{abstract}

Keywords: Poetry; Tradutology; Poetics. 
1. Apud. CASTELLO

BRANCO, Lúcia. A branca

dor da escrita: três tempos com

Emily Dickinson, 2003, p. 97.
É mais sutil - ter o Ouvido -

Enamorado - impotente - contente -

A Licença para reverenciar,

Que sublime privilégio

Ah, que Dote eu possuiria, se tivesse

A Arte de ensurdecer

Com Dardos de Melodia!

Emily Dickinson ${ }^{1}$

A partir do quadro de teorizações e posicionamentos críticos implícitos na poética da tradução proposta por João Barrento, o presente artigo tem por objetivo analisar três situações limítrofes na prática de tradução de poesia onde o gesto de verter se revela passível de analogias e correspondências com o próprio gesto de criar e onde o ato de enunciar se torna indissolúvel do gesto de escuta.

Antes de adentrar nas questões atinentes ao objeto e ao recorte propostos, cumpre lembrar que a tradutologia tem se revelado, nas últimas décadas, um dos terrenos mais férteis não apenas para as habituais investigações de cariz linguístico como também para o desenvolvimento de debates focados em questões nucleares à teoria da literatura e, principalmente, à literatura comparada e à poética, sem excluir perspectivas interdiscipli-nares, uma vez que a antropologia, a sociologia e a psicologia social têm sido convocadas a participar e trazer aportes a essas discussões. O denominador comum é a constatação de que o ato de traduzir, enquanto prática de escrita que se alimenta na recepção da palavra do Outro, implica na alteridade enquanto traço identitário e constitutivo de sua própria poética.

É igualmente importante lembrar que João Barrento tem sido considerado como um dos mais respeitados teóricos no campo da tradutologia em língua portuguesa, para o que colabora, sem a menor dúvida, sua extensa e intensa atividade como tradutor de alguns dos mais representativos autores da filosofia e da poesia - como Novalis, Kleist, Hugo von Hoffmanstahl, os expressionistas (Trakl, Benn), Celan, Kafka, Thomas Bernhard, Brecht, Walter Benjamin e Agamben. A enumeração desses nomes traça uma linhagem que parte do idealismo mágico alemão de inícios do século XIX (a escola de Jena) rumo aos domínios da teoria crítica no século $\mathrm{XX}$, perfazendo continuamente a travessia entre palavra poética $e$ palavra pensante.

As mais importantes reflexões e debates suscitados por João Barrento no âmbito da tradutologia se encontram reunidas em $O$ poço de Babel (publicado em 2002), sendo possível, 
ainda, localizar desdobramentos dessas proposições em outros textos, como "A terceira voz: quem fala no texto traduzido?" e, principalmente, "Fulgor e ritmo: tradução e escrita em Maria Gabriela Llansol e Herberto Helder".

Se tivéssemos que traçar o mapa das linhas de força atuantes nas reflexões de Barrento no âmbito da tradução de poesia, certamente obteríamos os quatro pontos cardeais que organizam um campo teórico bem definido.

Sob o primeiro ponto cardeal, a tradução - considerada não apenas como uma operação linguística - demandaria uma poética com o fito menos de sedimentar definições que propriamente o de detectar e refletir sobre os procedimentos estéticos e éticos que envolvem o ato de traduzir. Portanto, sua concepção de uma poética é voltada para a prospecção de cariz filosófico a respeito desse ato. O lastro teórico a partir do qual Barrento sustenta o equilíbrio e a viabilidade dessa construção especular é fornecido por aportes resultantes das reflexões teóricas postas em circulação com o romantismo alemão (sobretudo Novalis), a fenomenologia (Merleau-Ponty), o pensamento constelar de Walter Benjamin e o pensamento aporético de Derrida. A poética da tradução proposta por Barrento se configura por uma atenta audição de todas essas tradições e caminhos filosóficos, erguendo-se, assim, como uma arquitetura de ressonâncias vocais. E, fiel a tais ressonâncias, contém em si mesma a advertência para o fato de que cada tradução é, por si, "um ato inaugural que nega a possibilidade de estabelecer teorias gerais da tradução”2. Sua poética é, desse modo, uma "busca"3.

O segundo ponto cardeal firma a perspectiva pela qual, sendo a poesia um fenômeno de dicção (a emergência da Voz do Outro), a tradução de poesia seria, por conseguinte, também fenômeno de diç̧ão - ou seja: "um ato performativo desenvolvido contra um fundo intuitivo, interiorizado e necessariamente pessoal, de regras"4. Para Barrento, "alguma coisa se intromete entre as duas línguas no decurso da tradução" ${ }^{5}$. Essa intrusão de um terceiro elemento, além de deflagrar a experiência com jogos de alteridade implícita no ato de traduzir, instauraria a presença, no texto, de uma terceira voz. Segundo Barrento, as reflexões sobre a tradução - focadas na descrição de operações linguísticas - normalmente excluem de seu campo de reflexões essa presença de um terceiro no processo.

O terceiro ponto cardeal nos informa que essa dicção é sempre polifônica, pressupondo um contínuo diálogo entre vozes situadas em tempos históricos distintos e porventura distantes, já que a literatura se lhe apresenta desde sempre como uma "comunidade textual" 6 . Além disso, Barrento considera a terceira voz como múltipla, vez que composta por "restos e
2. BARRENTO, João. O arco da palavra, 2006, p. 133.

3. Ibidem, p. 175.

4. Ibidem, p. 133.

5. Ibidem, p. 133.

6. Ibidem, p. 175. 
7. Ibidem, p. 133.

8. Ibidem, p. 135.

9. Ibidem, p. 175. rastos diversos, não totalmente objetivados e não objetiváveis, da minha memória e do meu inconsciente linguístico, literário e cultural, mas que emergem, no texto em tradução, entre as duas línguas"7.

O quarto ponto cardeal é a abertura teórica para uma perspectiva culturalista no âmbito dos estudos de tradução, já que, para Barrento, a concepção da literatura como ponte, pressupondo, portanto, uma travessia (entre realidades não apenas linguísticas como sobretudo culturais distintas, quando não antipódicas), só é possível pelo fato de a literatura se realizar em rede:

as pontes da literatura e as redes da literatura, a literatura como ponte e como rede, a tradução como uma das pontes enredadas nestes enredos. A tradução como ponte, o tradutor como barqueiro, são já quase lugares comuns. A tradução tem a função da ponte, faz as vezes do barco: tra-ducere significa isso mesmo, levar para o outro lado, transportar para a outra margem ${ }^{8}$.

A partir de tais coordenadas críticas (que implicam, como vimos, posicionamentos teóricos), Barrento se propõe a estudar fenômenos específicos implicados no ato de traduzir. Em "Fulgor e ritmo", por exemplo, encontramos as sinalizações realizadas por Barrento no sentido de detectar o que ele chama de "passagens no limiar, ou nos extremos, do que se pode chamar tradução, nomeadamente de poesia", nas quais se verificaria a tentativa de aproximar os gestos da tradução e da criação poética, de forma a tornar flutuantes as fronteiras entre essas duas práticas de escrita.

Tais passagens no limiar entre tradução e criação seriam perceptíveis nos trabalhos de três autores portugueses atuantes, enquanto tradutores, na segunda metade do século XX - a saber: Maria Gabriela Llansol, Herberto Helder e Mario Cesariny - e é a partir desse foco que apresentaremos as reflexões que se seguem.

$$
* * *
$$

Começaremos a mapear esse território limiar por Maria Gabriela Llansol. Composta a partir de uma entranhada concepção da literatura como comunidade textual, a obra de Llansol propõe um diálogo constante com figuras literárias e históricas que, de alguma forma, colaboraram para sua formação enquanto escritora e leitora. Em Lisboaleipzig, por exemplo, propõe um encontro entre Fernando Pessoa e Bach, ao qual testemunhariam a esposa de Bach e um heterônimo feminino de Pessoa criado por Llansol. Uma dessas presenças fantasmáticas 
de escritores e poetas que se movem pela obra de Llansol é a de Emily Dickinson, flagrada no próprio ato de criação, na peleja com o "branco", nessa passagem de Parasceve em que a escrita é apresentada menos como uma forma de rompimento com o branco e mais como a transposição do branco (da parede, da tela mental) para o branco (do papel):

O que acontecera? Uma experiência muito simples. Inesperadamente ocorrera na sua vida uma experiência. A mulher - sentada no chão - de costas apoiada na parede, olhava com fixidez a outra parede branca do quarto - a parede que recebia menos claridade. Devido a esse pormenor existia entre o seu olhar e a parede um levíssimo diferencial no branco. A mulher não se distrai. Mantém o olhar fixo. Sem se dar conta, transfere branco para o branco. Olhos e paredes esvaem-se numa espécie de brancura dinâmica. Durante algum tempo é bom. Em seguida distrai-se, e cai no sentimento de que o espaço do quarto é restrito. "Há uma imensidade neste quarto exíguo", é o pensamento que, de raspão, atravessa o sentimento. Não é um devaneio. Fora um fato interrompido pela distração. Depois volta a transferir o branco para o branco ${ }^{10}$.

Depois de comparecer na obra de Gabriela Llansol como personagem, figura ou simplesmente voz comunicante (e estamos conscientes que a dificuldade em enquadrar seus textos nas categorias pré-programadas da teoria da literatura se dá não apenas no tocante à impermeabilidade que sua obra apresenta em vista da questão tipológica dos gêneros literários, mas também no que diz respeito aos elementos constitutivos desses tipos, como o personagem, o enredo etc), Dickinson mobilizou novamente sua atenção, quando, em 1995, Llansol verteu para o português Bilhetinhos com poemas, reunindo parte da correspondência e da poesia da autora norte-americana - versão sobre a qual nos demoraremos um pouco mais adiante.

De qualquer forma, é válido trazer à baila o que frisa Barrento a respeito da tradução de poesia: de maneira distinta à dos tradutores profissionais, o tradutor de poesia geralmente traduz poemas e autores com os quais tenha algum grau de empatia ou simpatia (intelectual ou poética). Portanto, sua escuta (considerada, aqui, como recepção da palavra do Outro) se dá a partir de um lugar bastante particular, onde se torna possível a analogia entre a arte tradutória e a arte amatória; porém, como no ritual medieval do assag, bem descrito por Agamben ${ }^{11}$, caberia ao tradutor o permanente adiamento da posse de seu objeto (sob pena de matá-lo), tomando, assim, o cuidado de não deixar que sua dicção pessoal se sobreponha à do autor traduzido. Para tanto, seria necessária a emergência de uma voz que não fosse nem a do autor nem a do tradutor, uma terceira VOZ, que se constituiria como ponto de tangência não apenas
10. LLANSOL, Maria Gabriela.

Parasceve, 2007, p. 35.

11. Cf. AGAMBEN, Giorgio.

Estâncias: a palavra e o

fantasma na cultura ocidental, 2007. 
12. LLANSOL, Maria

Gabriela. Inquérito is quatro confidências. Diário III, 1996, pp. 41-42.

13. Ibidem, p. 50. dos harmônicos dessas duas vozes primeiras, como também de toda a polifonia emanada pela comunidade textual. Desse modo, a tradução deixa de ser uma questão de mimetismo e passa a ser uma questão de dicção (num percurso que vai da escuta à enunciação, do silêncio ao som), conseguindo, nessa travessia, superar o choque antinômico característico de sua concepção como movimento-entre-dois por meio de uma abertura ontológica como movimento-entre-três. Longe de enclausurar o tradutor no silêncio, a terceira $\mathrm{VOZ}$ conduziria o gesto de tradução para a possibilidade da polifonia.

A construção da terceira voz em Maria Gabriela Llansol assume traços bastante particulares que se revelam capazes de aproximar a tradução e o próprio ato de criação. Isso fica bem claro quando retomamos as versões que Llansol propôs para os bilhetes e os poemas de Emily Dickinson. Nelas, a autora cria uma entidade intermediária entre si e a autora, a quem chama, sugestivamente, de Ana Fontes, num jogo de mascaramentos e revelações cujo estatuto é mais próximo do heterônimo do que mero pseudônimo (prática comum na tradução profissional, sobretudo quando o texto traduzido é polêmico ou ainda não ostenta o endosso crítico de seu status como literatura).

Como vimos, Dickinson não é a única escritora a povoar, ainda que em projeção fantasmática, a obra de Llansol. Rimbaud também é uma constante - e, como Dickinson, esse será outro autor a mobilizar sua atenção enquanto tradutora e enquanto criadora do que chamava drama-poesia (portanto, um modo de criação permanentemente aberto à voz do Outro). Em dado momento de Inquérito às Quatro Confidências. Diário III, a narradora propõe:

- Vergílio!

- Sim.

- Vamos mudar a cor e a grafia do $A$ de Rimbaud? Lembra-se do que ele escreveu? "A estrela choveu rosa no coração do teu ouvido atento/ $\mathrm{O}$ infinito rolou alvo no teu corpo, da nuca aos rins/ O mar orvalhou ruivo os teus seios de rubro cobre/ E o Homem sangrou negro no teu flanco sem fim"

- Ele identifica o $A$ negro e o Homem ${ }^{12}$.

Mais adiante, Llansol afirma: "eu não pertenço ao $A$ negro que tem este mundo em seu poder" ${ }^{13}$, identificando o $A$ com a negatividade ontológica, com as forças tanáticas e ctônicas, com o signo em trajetória descendente, com a corrupção da linguagem e do existir, tragados para dentro da zona antigravitacional do silêncio.

Daí que, para ela, é importantíssimo transformar o $A$ em Há: um percurso que vai do som inicial - que abre, com a voz, a primeira fenda definidora (já que $A$ é também um artigo 
definido e, assim, a definição prenunciadora da emergência da voz-identidade se instaura por uma fissura, por um ato de negatividade, o qual reside tanto na base formativa do sujeito como na própria linguagem verbal, já que, como percebeu Saussure, na língua só há diferenças) no interior do caos que compõe o reino das possibilidades - à interjeição que é verbo, que se fez verbo, como se do silêncio ao grito o ato poético sempre se constituísse em um sopro-expressão de estados emocionais, de estados do Ser, sabendo que só se chega de 0 (zero) ao $\mathrm{O}$ (numen) passando por $\mathrm{T}$, onde $\mathrm{T}=$ transformação, movimento pelo qual a Letra se aproxima do Homem, a Letra se mimetiza em Ser. E esse é nada menos que o projeto de sua própria escrita: "Escrevo para girar de $A$ em $H_{a}{ }^{\prime 14}$. Assim, ao mudar a cor e a grafia da primeira vogal do soneto rimbaudiano, reivindica um grau de liberdade que se justifica em face da perspectiva filosófica (de forma alguma infensa à dimensão ética, já que implica em um gesto inicial de escuta da voz e da palavra do Outro) que se estabelece entre seu texto e o de Rimbaud. Aqui teríamos um exemplo bastante nítido do que João Barrento detecta como o momento prometeico em que o tradutor se apossa do fogo divino do poema e se lança, de forma temerária, mas movida por incontornável imperativo ético, à travessia do sentido.

Nesse ponto, abro parêntesis para focalizar duas escolhas feitas por Llansol enquanto tradutora que, de par com a construção consciente de uma terceira voz distinta das vozes autorais que lhe são anteriores, demonstram como há toda uma arquitetura de ressonâncias vocais sustentando o edifício da tradução poética no interior de sua obra, sobretudo no que diz respeito às relações entre voz e identidade. Ou seja: concomitantemente ao esforço por uma tradução que é um movimento-de-três (completada pelo heterônimo Ana Fontes), persistem as nuances identitárias entre cada uma das entidades envolvidas nesse gesto de escrita. Além disso, as duas escolhas recaem sobre poetas cuja obra se situa no passado, o que faz com que às ideias de voz e identidade se una a de temporalidade - e, com ela, a questão da ressonância e da projeção fantasmática.

A primeira diz respeito aos poemas de Emily Dickinson. Como se sabe, a questão do tempo, em sua passagem e na permanente devoração de Cronos, ressoa de forma aberta na obra de Gabriela Llansol. Em Inquérito, ela nos lembra que "não há contemporâneos, mas elos de ausências presentes"15. De igual forma, ao verter Dickinson, Llansol esteve atenta às ressonâncias do tempo sobre a própria linguagem. Nos textos originais da autora norte-americana, marcados pelo uso reiterado de letras maiúsculas e por uma pontuação que é tanto personalíssima como laqueada por um brilho antigo e misterioso (já que Dickinson não capitalizava apenas as iniciais de substantivos
14. Ibidem, p. 51.

15. Ibidem, p. 48. 
16. Idem, Onde vais, dramapoesia?, 2000, p. 05 .
- como ocorria nas formas antigas da língua inglesa -, muito menos de substantivos abstratos, como se poderia esperar), Llansol, diferentemente de outros tradutores de Dickinson, mantém as letras maiúsculas nas iniciais, lendo-as tanto como índices (portanto, como pegadas ou marcas de uma presença física que já não mais existe) quanto como ícones (como traços identitários ou constituintes da própria forma). Se cada um mora no seu presente, o de Llansol e o de Dickinson momentaneamente se encontram, tendo a casa de Ana Fontes por abrigo ou invólucro.

Para Barrento, esse acúmulo de temporalidades em Llansol configuraria uma poética da tradução enquanto trabalho de vegetalização. Lembremos que a própria autora ressalta em Onde vais, Drama-Poesia?. "clorofila, a primeira matéria do poema" ${ }^{\prime 16}$. Sob essa ótica, vegetalizar um poema (mediante o gesto de tradução) consistiria em transpor suas nervuras e seus rizomas, e assim, por mais paradoxal, tentar remetê-lo de volta à cena de sua origem, à matéria primeira e inaugural do poema.

Essa impressão é reforçada pela segunda escolha de Llansol, que diz respeito às traduções que fez de Rimbaud. Nelas, optou por reconstituir, em língua portuguesa, apenas as imagens que se encadeiam ao longo do poema, prescindindo da mimese rítmica implicada na métrica (isometria). Essa escolha se funda em dois pressupostos teóricos: o primeiro, o de que a fanopeia (estrato imagético de um poema) seria sua única camada universalmente comunicável e que não seria passível de perda pela tradução; o segundo, o de que os gestos inerentes à criação poética e à tradução de poesia vão além da mera questão de formas (embora não apaguem tais marcas inegavelmente identitárias), cabendo, dentro de si, o salto do ôntico rumo ao ontológico que caracteriza a palavra poética, quer em estado de criação, quer em estado de tradução.

$$
* * *
$$

A segunda situação-limiar entre tradução e criação diz respeito aos poemas mudados para o português pelo poeta Herberto Helder.

Ao longo de cinco livros, Helder tem compilado poemas pertencentes a tradições literárias não-ocidentais, algumas delas mortas, outras agonizantes ou ainda precariamente vivas em suas manifestações orais. Desconhecendo as línguas originais em que os textos foram compostos, Herberto Helder se vale de textos intermediários, já que antropólogos e etnólogos efetuam um trabalho inicial de estabilização semântica das palavras, a partir do qual se dá o trabalho do poeta-tradutor. Helder prefere chamar suas traduções de poemas mudados e a expres- 
são ressalta como os poemas surgidos em língua portuguesa se constituem, efetivamente, metamorfoses dos textos de partida.

Nas mudanças de Herberto Helder impõe-se, sempre, a questão da organização do material. Um volume de traduções como As magias, apresenta os textos de forma a provocar ressonâncias de uns sobre os outros. Assim, convivem, lado a lado, Henri Michaux, os índios comanche e os pigmeus. Os textos enfeixam um grupo de poemas que, independentemente da questão técnico-tradutológica, deveriam, de qualquer forma, entrar em circulação no interior da poesia em língua portuguesa, já que preenchem vazios notados em seu percurso. A solução encontrada por Herberto Helder parece-nos ser justamente o gesto de situar, no processo de mudança, a poesia como código dentro do código. Desse modo, ao mudar os poemas, devolve-os ao lugar de origem, que é o da poesia enquanto prática milenar.

Sob a abordagem para o ato de traduzir proposta por Herberto Helder, torna-se difícil pensar num poema mudado como esse que se encontra em As Magias, recolhido entre os índios comanches norte-americanos, sem comunicá-lo com outras tradições, como, por exemplo, a vanguarda europeia em suas manifestações mais extremas de poesia sonora ou etnoliteratura:

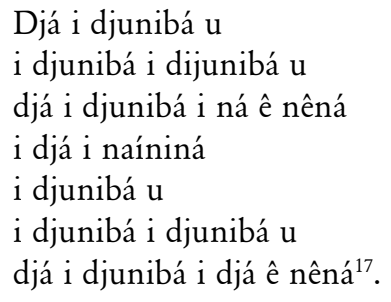

Embora pertencente à tradição oral de nativos da América do Norte (o que sabemos desde o princípio, já que isso é sinalizado no título do poema) e mesmo que desconheçamos por completo se esses sons possuem algum significado na língua de origem, é praticamente impossível ler esse poema, no contexto da poesia moderna, sem remeter aos experimentos de poesia fonética e de poesia sonora intentados pela vanguarda europeia, desde Christian Morgestern até os letristas, passando por Marinetti (com seu projeto de poesia onomatopaica, seguido por diversos outros poetas do futurismo italiano) e Pierre-Albert Birot:

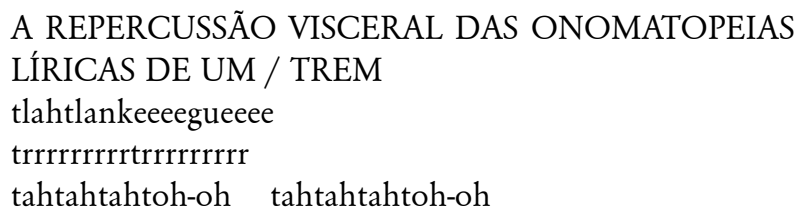

17. HELDER, Herberto. As magias, 1987, p. 11. 
18. Ibidem, p. 15.

19. BARRENTO, João. $O$ arco da palavra, 2006, p. 181.

\author{
cuhrrrrrrrrrrrr \\ cuhrrrrrrrrrrr \\ cuhrrrrrrrrrrrr \\ foofoofoofoofoofoo \\ fahfahfahfah \\ dsahdsahdsahdsahdsah \\ tsahtsahtsahtsah ${ }^{18}$.
}

De igual forma, é dificil compreender as ressonâncias desse poema trazido de uma tradição oral sem nos lembrarmos das investigações levadas a cabo pelos futuristas russos no sentido de definir os valores sonoros de um poema como seus traços identitários e constitutivos universais, de que resultaram tanto a poesia Zaum (que os futuristas russos chamavam de poesia transmental, marcada pelo que consideravam o uso selvagem, inflamado e explosivo da linguagem) como o interesse de seus teóricos por fenômenos linguísticos como a glossolalia e o gibberish.

Repare-se que Herberto Helder se limita a inserir a transcrição fonética do texto no interior de sua antologia As Magias, sem propor qualquer mediação (ou metamorfose) na superfície do texto. Ele se recusa a nos informar se aquelas palavras constituem um puro objeto sonoro ou se elas articulam sentidos e imagens estáveis. É como o texto dispensasse tradução, já que ele seria uma realidade acústica por si e, como tal, sua experiência estaria ao alcance do receptor de qualquer língua ou cultura. Assim, ao transpor para a página em branco, sem quaisquer alterações, a transcrição fonética de um texto oral de uma tradição longínqua (cuja própria noção de poesia só se possa aplicar com certa indiferença pela precisão terminológica no campo da investigação antropológica, já que, em sociedades como a que se recolheu o texto, essas formulações verbais se inserem no quadro social mais amplo das práticas quotidianas que buscam o reencantamento da vida e da celebração e abertura para o sagrado), Herberto Helder opera talvez a maior das metamorfoses, pois esse novo poema não apenas desafia a noção de que as imagens seriam o único elemento de comunicação universal num poema, como também ocupa um espaço vazio, já que une o arcaico ao moderno e, por meio dessa prática transcultural, coloca em circulação (se não inaugura) propostas estéticas que não teriam sido aventadas no interior do sistema da própria moderna poesia portuguesa - como o poema fonético, a poesia sonora ou mesmo a ideia de um primitivismo moderno, os quais apresentam reiteradas manifestações nas demais literaturas europeias já no começo do século XX. Como bem ressalta Barrento, a perspectiva tradutológica de Herberto Helder é a de que "a poesia é então uma faculdade, um dom comum a várias formas de dizer e de fazer humanos, num espaço criativo de metamorfoses permanentes" ${ }^{19}$. 
A última situação-limite é trazida à luz por Mario Cesariny, com suas traduções seguindo o procedimento a que denominou cabala fonética.

Cesariny, como se sabe, foi, além de um dos mais representativos poetas da literatura portuguesa do século XX, também importante tradutor, já que verteu para o português textos de Antonin Artaud, Novalis e Rimbaud. Sua poesia estabelece notável diálogo entre tradição e vanguarda, tendo em vista o agenciamento que faz, em seus poemas, tanto de formas estáveis da tradição ocidental (como o soneto e a quadra) como de experimentos com estados específicos de criação postos em circulação pelo surrealismo (caso do cadáver esquisito e do poema-inventário).

Prova desse diálogo permanente entre a estética da permanência e a estética da ruptura são as traduções para um soneto de Góngora em que Cesariny tomou parte. Há que se dizer "tomou parte", pois a tradução nesse caso é praticada sob horizonte coletivo, se não vejamos. Inicialmente, o poeta Peter Marr traduziu um soneto de Góngora do espanhol para o inglês, guiado unicamente pelas sugestões sonoras do poema. Essa tradução inicial foi, então, traduzida para o português por Mario Cesariny, que, como Marr, se ateve unicamente às sugestões que os sons causavam. A versão em português, por sua vez, foi mudada (sempre em consonância com as sugestões sonoras) para o tcheco, que, por sua vez, foi revertida para o espanhol por José-Francisco Aranda.

Essa prática - em muito parecida com a brincadeira chamada telefone sem fio e com o cadavre-exquis conforme praticado pelos surrealistas - não apenas aproxima tradução e poesia ao jogo, como, nesse processo, aproxima e irmana os gestos da tradução e da criação. Como sabemos, a libertação do material artístico é nuclear na poética de Cesariny, como fazem prova seus poemas-inventários (nos quais poetiza objetos banais ou inusitados, desde sempre considerados materiais não-nobres e inadequados para o fazer poético). Por esta razão, nada mais consequente que a libertação do material poético seja atingida, também, pelo gesto da tradução.

Saliente-se que ela é feita com notável senso lúdico, já que o próprio jogo é uma forma de reorganização da realidade a partir de valores outros que os da sociedade de acumulação.

Desnecessário salientar o especial interesse que Freud manifestou por jogos de linguagem ou ainda o fato de que, a partir da segunda metade do século $\mathrm{XX}$, se intensificarão as investigações no território da psicanálise sobre as relações entre jogo e criatividade, de que fazem testemunho obras de Winnicott, Hanna Segall e Marion Milner. Segundo Winnicott, o jogo tem o poder de colocar crianças e adultos num 
20. PIGNATARI, Décio.

Semiótica e Literatura, 2004, p. 57. estado de liberdade muito próximo ao da criação - e, para o psicanalista inglês, o indivíduo só descobre sua persona quando se mostra criador.

Sendo escrita sob a égide do jogo, é consequente que a tradução por cabala fonética provoque e reivindique para si modos específicos de leitura, já que, com a entrada em cena da lógica do jogo, temos uma vez mais a ruptura com as convenções e os protocolos do gesto de tradução.

Nesse ponto, é instrutivo recorrer aos conceitos preconizados pela semiótica de Peirce, a fim de compreender melhor o que está em questão. Ao fazer o caminho inverso da ordem semiótica habitual - ou seja: partindo de um signo convencional (terceiridade; legissigno) para chegar numa forma sonora pura (primeiridade), seguindo, portanto, a ordem decrescente -, as traduções por cabala fonética nos fazem lembrar que a palavra poética implica no descondicionamento permanente e renovado contra as rotinas linguísticas. Ao caminhar das generalizações coercitivas do legissigno (palavra em estado de chumbo, com a qual se forjam algemas, grilhões e cadeias estritamente lógicas a partir do sequenciamento de constrições binárias) rumo às possibilidades múltiplas e à indeterminação da primeiridade - já que esta última qualidade de signo "labora no campo do possível e do indeterminado" ${ }^{20}$-, verifica-se o retorno do horizonte utópico da comunicabilidade universal pressuposto na tradução e na própria poesia, mas mediante outra proposição: a palavra poética, carregada de uma intenção lúdica (que é, em grande medida, resposta à busca reiterada de um lidar com o signo verbal enquanto meio de reencantamento do mundo), retomaria, em seu transporte mercurial, a capacidade de descondicionar a linguagem e o ser, presos na malha imobilizadora tramada por suas rotinas (que, em última instância, são sintoma de falsa consciência), inclusive as verbais.

É assim que a tradução por cabala fonética, sob a superfície enganosa da simplicidade técnica e da jocosidade, reafirma a necessidade de a poesia - como toda forma de saber - se conduzir à alegria, enquanto gaia ciência, provando que é possível, pelo fazer poético, reverter o curto-circuito conceitual gerado pela linguagem em seu modo de funcionamento prosaico, binário e excludente. Se, como ensina a psicanálise, todo problema de gozo é um problema de linguagem, a tradução de poesia implicaria, pois, não apenas a emergência de uma voz, e sim a tentativa prometeica de libertação da própria linguagem e dos materiais com que se faz o poema, a ser traduzido ou não (já que o naufrágio no silêncio é sempre possível, quando não em si uma resposta), momento num processo mais amplo, que propõe, por meio de passagens-limite, um percurso do ôntico rumo ao ontológico. 
A poética da tradução como traçada por Barrento é um processo de escuta e reconhecimento da Voz do Outro, uma sondagem dos limites, das fronteiras, das passagens. Com isso, incorre a tradução num necessário gesto de descentramento - no sentido de retirada do foco sobre a primeira pessoa, ou mesmo sobre os dois códigos, seguida pela emergência de uma terceira - que não é código, e sim voz (portanto, fenômeno de dicção que implica tanto o descentramento como a escuta e o reconhecimento da Voz do Outro).

Por conta disso, interessam-lhe os esforços de tradução como os intentados por Maria Gabriela Llansol, Herberto Helder e Mario Cesariny. Constituem-se nada menos que situações abertas no interior do espaço figurado pelo ato de traduzir que o encaminham na direção das margens da linguagem (em uma movência ex-cêntrica, quando não centrífuga), porquanto consigam - em seu estatuto limítrofe entre o traduzir e o criar, entre o ouvir e o dizer, entre a palavra poética e a palavra pensante - encenar a travessia do ôntico rumo ao ontológico que a linguagem verbal potencialmente carrega em si. Nessas situações por Barrento intituladas passagens-limite, encontramos, com força máxima, aquelas "marcas de uma duplicidade, de uma ambivalência, de uma relação tensa, e mesmo conflitual, entre um idem e um alter, entre um Mesmo e um Outro, entre um original e a rede possível de suas traduções" ${ }^{21}$. Ao explicitarem a intrusão de uma outra voz no processo, essas passagens-limite igualmente tornam audíveis as vozes (e, por conseguinte, os corpos que as emitem) que compõem a comunidade textual e nos lembram como o ato de traduzir pressupõe escolhas não apenas estéticas, como também éticas, já que é contra o pano de fundo de nossos repertórios linguísticos, literários e culturais que se dá a experiência da tradução como metamorfose permanente das relações entre ouvir e falar.
21. BARRENTO, João. $O$ arco da palavra, 2006, p. 135. 


\section{Referências}

AGAMBEN, Giorgio. Estâncias: a palavra e o fantasma na cultura ocidental. Belo Horizonte: Editora da UFMG, 2007.

BARRENTO, João. O arco da palavra. São Paulo: Escrituras, 2006.

CASTELLO BRANCO, Lúcia. A branca dor da escrita: três tempos com Emily Dickinson. Rio de Janeiro: 7Letras; Belo Horizonte: UFMG, 2003.

CESARINY, Mario. Primavera autônoma das estradas. Lisboa: Assírio \& Alvim, 1980.

Helder, Herberto. As magias. Lisboa: Hiena, 1987.

LLANSON, Maria Gabriela. Inquérito às quatro confidências. Diário III. Lisboa: Relógio d'Água, 1996.

Onde vais, drama-poesia? Lisboa: Relógio d'Água, 2000.

___. Parasceve. Lisboa: Relógio d'Água, 2007.

PIGNATARI, Décio. Semiótica e Literatura. São Paulo: Ateliê, 2004. 